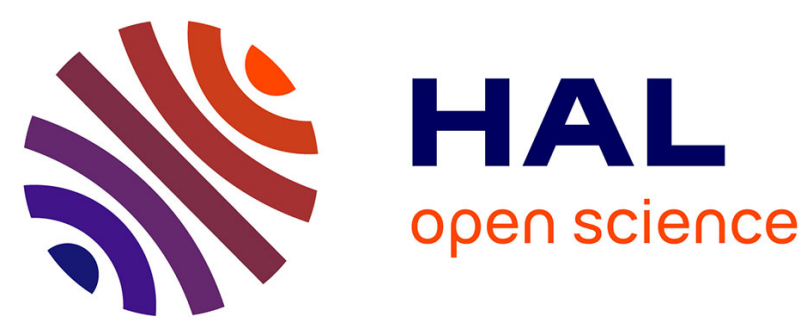

\title{
Understanding Mono- and Bivalent Ion Selectivities of Nanoporous Graphene Using Ionic and Bi-ionic Potentials
}

Mandakranta Ghosh, Lukas Madauss, Marika Schleberger, Henning Lebius, Abdenacer Benyagoub, Jeffery Wood, Rob Lammertink

\section{To cite this version:}

Mandakranta Ghosh, Lukas Madauss, Marika Schleberger, Henning Lebius, Abdenacer Benyagoub, et al.. Understanding Mono- and Bivalent Ion Selectivities of Nanoporous Graphene Using Ionic and Bi-ionic Potentials. Langmuir, 2020, 36 (26), pp.7400-7407. 10.1021/acs.langmuir.0c00924 . hal03042525

\section{HAL Id: hal-03042525 \\ https://hal.science/hal-03042525}

Submitted on 11 Dec 2020

HAL is a multi-disciplinary open access archive for the deposit and dissemination of scientific research documents, whether they are published or not. The documents may come from teaching and research institutions in France or abroad, or from public or private research centers.
L'archive ouverte pluridisciplinaire HAL, est destinée au dépôt et à la diffusion de documents scientifiques de niveau recherche, publiés ou non, émanant des établissements d'enseignement et de recherche français ou étrangers, des laboratoires publics ou privés. 


\title{
Understanding Mono- and Bivalent Ion Selectivities of Nanoporous Graphene Using lonic and Bi-ionic Potentials
}

\author{
Mandakranta Ghosh, Lukas Madauß, Marika Schleberger, Henning Lebius, Abdenacer Benyagoub, \\ Jeffery A. Wood,* and Rob G. H. Lammertink*
}

Cite This: Langmuir 2020, 36, 7400-7407

Read Online

ACCESS 1

Llll Metrics \& More

Article Recommendations

Supporting Information

ABSTRACT: Nanoporous graphene displays salt-dependent ion permeation. In this work, we investigate the differences in Donnan potentials arising between reservoirs, separated by a perforated graphene membrane, containing different cations. We compare the case of monovalent cations interacting with nanoporous graphene with the case of bivalent cations. This is accomplished through both measurements of membrane potential arising between two salt reservoirs at different concentrations involving a single cation (ionic potential) and between two reservoirs containing different

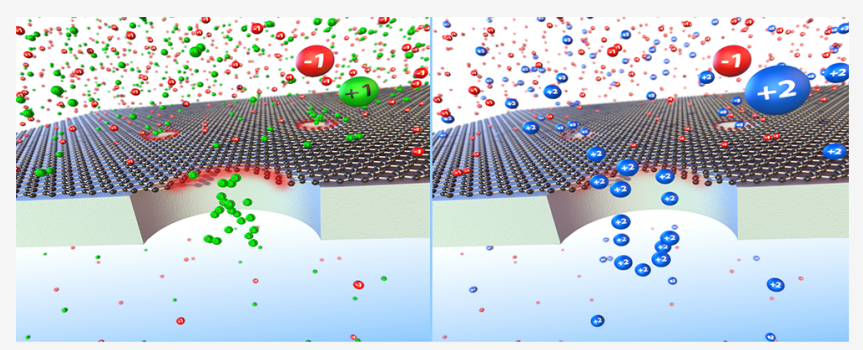
cations at the same concentration (bi-ionic potential). In our present study, Donnan dialysis experiments involve bivalent $\mathrm{MgCl}_{2}, \mathrm{CaCl}_{2}$, and $\mathrm{CuCl}_{2}$ as well as monovalent $\mathrm{KCl}$ and $\mathrm{NH}$ For all salts, except $\mathrm{CuCl}_{2}$, clear Donnan and diffusion potential plateaus were observed at low and high salt concentrations, respectively. Our observations show that the membrane potential scaled to the Nernst potential for bivalent cations has a lower value $(\approx 50 \%)$ than for monovalent cations $(\approx 72 \%)$ in the Donnan exclusion regime. This is likely due to the adsorption of these bivalent cations on monolayer graphene. For bivalent cations, the diffusion regime is reached at a lower ionic strength compared to the monovalent cations. For $\mathrm{Mg}^{2+}$ and $\mathrm{Ca}^{2+}$, the membrane potential does not seem to depend upon the type of ions in the entire ionic strength range. A similar behavior is observed for the $\mathrm{KCl}$ and $\mathrm{NH}_{4} \mathrm{Cl}$ membrane potential curves. For CuCl 2 , the membrane potential curve is shifted toward lower ionic strength compared to the other two bivalent salts and the Donnan plateau is not observed at the lowest ionic strength. Bi-ionic potential measurements give further insight into the strength of specific interactions, allowing for the estimation of the relative ionic selectivities of different cations based on comparing their bi-ionic potentials. This effect of possible ion adsorption on graphene can be removed through ion exchange with monovalent salts.

\section{INTRODUCTION}

Ion transport through charge-selective interfaces has been studied extensively in the scientific community as a result of their relevance in applications, such as filtration, desalination, and sensors. ${ }^{1-3}$ Most of the studies to date have focused on dense ion-exchange membranes or porous networks. ${ }^{1,2,4-6}$ Graphene as a membrane material has sparked studies to develop a fundamental understanding of ion transport through this material. ${ }^{7-14}$ Graphene has a thickness of only $0.34 \mathrm{~nm}$ (single layer), suggesting that ion transport through nanoporous graphene is quite different versus three-dimensional (3D) nanoporous materials. Because a pore will be atomically thin, transport through it will be dominated by entrance/exit effects. Our main motivation in this study is to provide further understanding of the interaction of different cations with graphene surfaces and its influence on the ion transport through atomically thin membranes.

In our previous work, we experimentally investigated the interaction of monovalent cations with a monolayer perforated graphene membrane supported on a polyethylene terephthalate (PET) foil. ${ }^{15,16}$ Our findings showed that the total electrical potential across a single-layer graphene membrane separating different ion concentration reservoirs could be described as a cation-selective layer using a modified version of the Teorell-Meyer-Sievers (TMS) theory, which is a continuum theory designed for thicker membranes. ${ }^{17,18}$ At low electrolyte concentrations, the potential enters into a Donnan-like regime where the potential versus concentration at a fixed concentration ratio between compartments shows a plateau. At high salt concentrations, a diffusion potential based on the ionic mobility contrast of the cation and anion was retrieved. For single-layer graphene, the ratio of diffusion coefficients of the anion and cation in the membrane was consistent with the ratio of values in bulk solution, which in general is not observed in typical ion-exchange membranes. ${ }^{19}$

Received: April 1, 2020

Revised: June 4, 2020

Published: June 4, 2020 
Our previous study with monovalent cations involved three salts $\left(\mathrm{K}_{2} \mathrm{SO}_{4}, \mathrm{KCl}\right.$, and $\left.\mathrm{LiCl}\right)$, resulting in three distinct Donnan plateaus. The reason for these three distinct Donnan plateaus is interesting to investigate because it provides further knowledge of the ion interaction with the graphene surface. There are some studies to understand the interaction of any particular ion with the graphene oxide surface. ${ }^{20,21}$ Studies that compare the behavior of different cations to graphene surfaces are limited, although such studies are abundant for conventional nanofiltration membranes. In recent work, Khannanov et al. have experimentally shown the differences in the concentration profile for ions having different valencies. ${ }^{22}$ Rosenberg et al. have shown that cation selectivity for multivalent ions is lower than that for monovalent ions. ${ }^{23}$ Caglar et al. showed that, for a tetravalent cationic salt $\left(\mathrm{HfCl}_{4}\right)$, graphene with intrinsic defects shows a transition from cationselective to anion-selective behavior. This transition happened even at constant concentrations of $\mathrm{HfCl}_{4}$ on either side of two reservoirs containing different concentrations of $\mathrm{KCl}$, which is a strong indication that adsorption of $\mathrm{HfCl}_{4}$ led to charge inversion as a result of adsorption of the high-valence cation on an initially negatively charged surface. ${ }^{24}$ There are a number of molecular dynamics (MD) simulation studies to understand the interaction of ions and the salt rejection mechanism of nanoporous graphene. ${ }^{25-30}$ These studies reveal that the salt rejection highly depends upon the pore diameter, the type of ions passing through the pores, and the chemical functionality of the pore. Jiang et al. have studied the double-layer structure at the graphene electrode/electrolyte interface for different monovalent electrolytes. Their study shows that each ion has its distinct electrical double layer (EDL) at the graphene electrode surface, and the potential distribution in the EDL is determined by the ion type. ${ }^{27}$ The MD simulation study of Cohen-Tanugi et al. indicated that functional groups at the pores determine the salt rejection. ${ }^{25}$ Hydrogenated pores have higher salt rejection than hydroxylated pores because hydroxyl groups substitute the water molecules from the ion hydration shell. We need to stress here that, in these MD simulations, ion dissociation of the graphene hydroxyl groups was not taken into account. He et al. have shown that nanopores with four carboxylate groups have a preferential transport of $\mathrm{K}^{+}$ions over $\mathrm{Na}^{+}$, which is explained by the crystal field theory. ${ }^{28}$ The work of Ruan et al. shows that $\mathrm{Mg}^{2+}$ ions are transported more easily than $\mathrm{Li}^{+}$ions. ${ }^{30}$ All of these studies indicate that the functional groups at graphene nanopores have specific ion interactions that are crucial in the transmembrane transport of ions.

The ion interaction can be understood by membrane potential experiments. ${ }^{31}$ In our current study, we have conducted bi-ionic potential measurements, which allows us to study the interaction between graphene membranes and different counterions. ${ }^{18,32-35}$ To further investigate the impact of cations on charge transport in nanoporous single-layer graphene, we include bivalent cations in our present study. Multivalent ions have a higher ability to screen surface charge than monovalent counterions. This can lead to inversion of surface charge. ${ }^{36-40}$ This behavior is often observed in ionexchange membranes and resins as a result of the adsorption of multivalent cations on the fixed negative charges. ${ }^{23,41}$ The nature of the surface charge on the graphene pore surface has been debated in the literature, with the presence of surface functional groups or hydroxide adsorption being its origin. ${ }^{12,24}$ In either case, the $\mathrm{pH}$ of the solution reservoirs can have a strong influence on the resulting ion selectivity. In this work, we work at a fixed $\mathrm{pH}$. Our ongoing work does indicate that the cation or anion selectivity of nanoporous graphene is $\mathrm{pH}$ dependent, which will be reported in a future paper. Galizia et al. have shown that, even at low salt concentrations, the salt sorption coefficient is higher for multivalent counterions than monovalent counterions, as is expected as a result of the weaker Donnan exclusion for multivalent salts and consistent with the charge inversion observed by Caglar et al. ${ }^{24,41}$ In this work, we have expanded the ion transport study for bivalent cations $\left(\mathrm{Mg}^{2+}, \mathrm{Ca}^{2+}\right.$, and $\left.\mathrm{Cu}^{2+}\right)$ through perforated graphene and have compared the results to the monovalent case $(\mathrm{KCl}$ and $\mathrm{NH}_{4} \mathrm{Cl}$ ). We have conducted bi-ionic potential measurements to understand the differences in Donnan plateaus for different salts. This measurement quantifies the differences in the affinity of graphene toward different cations, providing a useful tool for assessing the effect of different ions on the charge selectivity of graphene or other nanoporous materials. We also examined how the surface adsorption of bivalent cations affects the membrane potential characteristics and systematically investigated the membrane recovery process.

\section{THEORETICAL BACKGROUND}

In our previous paper, we have described the potential difference between two reservoirs at different ion concentrations separated by a perforated graphene membrane using a modified version of the TMS theory. ${ }^{15}$ The TMS theory was derived to describe the potential difference across dense continuous ion-exchange membranes. ${ }^{17}$ The theory describes the membrane potential as a sum of Donnan and diffusion potential. The Donnan potential is generated as a result of the well-known Donnan exclusion of co-ions by the membrane, and the diffusion potential is generated as a result of corresponding mobility contrast of co-ions and counterions inside the membrane. At a very low ionic concentration of the electrolyte, the fixed ion concentration of the membrane is typically much higher than the electrolyte concentration. In this regime, the Donnan potential of the membrane dominates and the membrane potential is only dependent upon the electrolyte concentration ratio. With an increase in the electrolyte concentration (or ionic strength), the membrane potential decreases toward the diffusion potential. At a very high concentration, when the electrolyte concentration is comparable or larger than the fixed ion concentration of the membrane, the diffusion potential starts to dominate and the membrane potential again reaches a plateau. By adjustment of the Donnan potential term to take into account the nonidealities of the graphene membrane, we were able to describe our experimental data. The modified TMS model is given in the following equation:

$$
\begin{aligned}
& \Delta \psi=-\alpha\left(\frac{R T}{F} \ln \frac{C_{2}}{C_{1}} \frac{\sqrt{\bar{C}_{\mathrm{R}}^{2}+4 C_{1}^{2}}+\bar{C}_{\mathrm{R}}}{\sqrt{\bar{C}_{\mathrm{R}}{ }^{2}+4 C_{2}^{2}}+\bar{C}_{\mathrm{R}}}\right) \\
& -\frac{R T}{F} \bar{u} \ln \frac{\sqrt{\bar{C}_{\mathrm{R}}^{2}+4 C_{2}^{2}}+\bar{u} \bar{C}_{\mathrm{R}}}{\sqrt{\bar{C}_{\mathrm{R}}^{2}+4 C_{1}^{2}}+\bar{u} \bar{C}_{\mathrm{R}}}
\end{aligned}
$$

where $R$ is the universal gas constant, $T$ is the temperature, $F$ is the Faraday constant, $\bar{C}_{R}$ is the fixed ion concentration in the membrane, $C_{1}$ is the high-concentration solution, and $C_{2}$ is the low-concentration solution, and $\alpha$ is the non-ideality factor. $\bar{u}$ is a term representing the different diffusion rates of the cation $\left(\bar{u}_{+}\right)$compared to the anion $\left(\bar{u}_{-}\right)$in the membrane, given by 


$$
\bar{u}=\frac{\bar{u}_{+}-\bar{u}_{-}}{\bar{u}_{+}+\bar{u}_{-}}
$$

When our experimental data are fitted with the modified TMS model, we obtain the non-ideality factor $\alpha$, the fixed ion concentration of the membrane $\bar{C}_{R}$, and the ratio of diffusivities of the anion to cation $\bar{u}_{-} / \bar{u}_{+}$.

Figure 1 shows the membrane potential for monovalent $\mathrm{KCl}$ and bivalent $\mathrm{MgCl}_{2}, \mathrm{CaCl}_{2}$, and $\mathrm{CuCl}_{2}$, as predicted by the

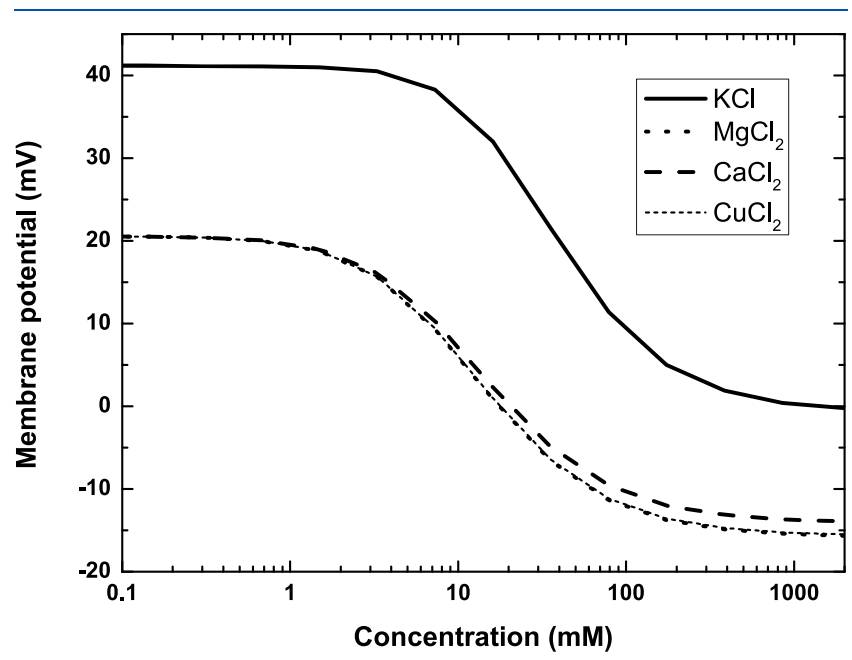

Figure 1. Membrane potential versus concentration $\left(C_{2}\right)$ predicted by the TMS theory for $\mathrm{KCl}, \mathrm{MgCl}_{2}, \mathrm{CaCl}_{2}$, and $\mathrm{CuCl}_{2} . C_{1} / C_{2}$ is 5 for all cases.

TMS theory. According to the theory, for $\mathrm{KCl}$, the Donnan plateau is expected at $41.3 \mathrm{mV}$ (for a $5: 1$ concentration ratio) and a diffusion plateau at around $0 \mathrm{mV}$ (as a result of the similar diffusivities for $\mathrm{K}^{+}$and $\mathrm{Cl}^{-}$, assuming bulk diffusivity values). The membrane potential for bivalent salts is predicted from the TMS theory for 2:1 salts. ${ }^{42}$ For bivalent salts, the predicted Donnan plateau is $20.6 \mathrm{mV}$, which is generated as a result of the Donnan exclusion of the $\mathrm{Mg}^{2+}, \mathrm{Ca}^{2+}$, and $\mathrm{Cu}^{2+}$ ions at low electrolyte concentrations, while the diffusion plateau is at around $-15 \mathrm{mV}$ for $\mathrm{MgCl}_{2}$, around $-14 \mathrm{mV}$ for $\mathrm{CaCl}_{2}$, and around $-16 \mathrm{mV}$ for $\mathrm{CuCl}_{2}$, which are generated because $\mathrm{Cl}^{-}$ions have a higher diffusivity than $\mathrm{Mg}^{2+}, \mathrm{Ca}^{2+}$, and $\mathrm{Cu}^{2+}$ ions. $^{43}$

To understand the differences in the Donnan plateau for different cations and further quantify the degree of specific ion interactions, bi-ionic potential measurements are conducted. A bi-ionic potential develops when a cation-exchange membrane separates two different electrolyte solutions with different counterions but the same co-ions. If the concentration of both of the reservoirs is the same, the affinity is quantified by a selectivity factor $K_{A}^{\mathrm{B}}$. This selectivity factor is 1 when the ions have similar affinities, and the factor is not equal to 1 when the membrane has differences in affinities between two cations. For two cations $\mathrm{A}$ and $\mathrm{B}$, the bi-ionic potential $E_{\mathrm{Bi}}$ is given by the formula

$$
E_{\mathrm{Bi}}=-\frac{R T}{z F} \ln \left(\frac{\bar{u}_{\mathrm{B}}}{\bar{u}_{\mathrm{A}}} K_{\mathrm{A}}^{\mathrm{B}}\right)
$$

where $R$ is the molar gas constant, $T$ is the temperature of the solution, $z$ is the valence, and $F$ is the Faraday constant. $\bar{u}_{\mathrm{B}}$ and
$\bar{u}_{\mathrm{A}}$ are the diffusion coefficients of the cations inside the membrane.

In this work, we will show that the factor $K_{\mathrm{A}}^{\mathrm{B}}$ can be related to the non-ideality factor $\alpha$ that we previously introduced. In this way, we can quantify the differences in affinity of graphene toward different cations.

\section{EXPERIMENTAL METHOD}

The experimental method is similar to that described in our previously published paper. ${ }^{15}$ We have used commercially available chemical vapor deposition (CVD)-grown monolayer graphene. The poly(methyl methacrylate) (PMMA)-coated graphene is transferred to a $13 \mu \mathrm{m}$ thin PET support, which provides robustness to the membrane and ease of handling. Swift heavy ion irradiation (SHI) is used to create holes in the monolayer graphene at the IRRSUD beamline facility at GANIL, France. ${ }^{16}$ The energy of the irradiation is $0.56 \mathrm{MeV} / \mathrm{u}(\mathrm{Pb})$, and the fluence is $5 \times 10^{7}$ ions $/ \mathrm{cm}^{2}$. During the irradiation, pores are created in graphene and tracks in the PET support. With the assumption that each ion creates a single pore, we expect $5 \times 10^{7}$ pores to be created in the graphene per $\mathrm{cm}^{2}$ area. ${ }^{44}$ Pore diameters are expected to be on the order of $1-10 \mathrm{~nm}^{45}$ To create holes along the ion tracks in the PET support, we etch the composite membrane in $3 \mathrm{M}$ sodium hydroxide solution at $50{ }^{\circ} \mathrm{C}$ for 34 min. During etching, the PMMA layer protects the graphene layer from the etching solution. The etching process creates somewhat truncated holes in PET. Nevertheless, the PET pores are much larger than the graphene pores and do not influence the ion transport through the graphene pores. The experimental results for the PET support without any graphene layer is shown in the Supporting Information. After the etching process, the PMMA layer is removed by immersing it in acetone and the graphene/PET composite membrane is obtained. We measured the membrane potential across the composite membrane by placing it between two reservoirs containing salt solution with high $\left(C_{1}\right)$ and low $\left(C_{2}\right)$ ionic strength at a constant ratio of 5 . The potential is measured with the help of two calomel reference electrodes and a potentiostat. We vary the ionic strength of both reservoirs while keeping a constant ionic strength ratio $\left(C_{1} / C_{2}=5\right)$. We have used $\mathrm{MgCl}_{2}, \mathrm{CaCl}_{2}$, and $\mathrm{CuCl}_{2}$ as bivalent salts and $\mathrm{KCl}$ and $\mathrm{NH}_{4} \mathrm{Cl}$ as monovalent salts for comparison. The solution is continuously circulated by a pump to minimize concentration gradients near the membrane. The temperature is regulated at $25{ }^{\circ} \mathrm{C}$ with a temperature bath. For the bi-ionic potential measurements, we have kept the same experimental setup but maintained the same ionic strength of the different cations on both sides of the membrane and measured the potential.

\section{RESULTS AND DISCUSSION}

In Figure 2, the experimentally measured membrane potential is shown as a function of the ionic strength of the lowconcentration reservoir along with the fit using the modified TMS model. On the basis of the observed positive membrane potential, we can conclude that our membrane is cationselective. Our goal is to understand the interaction of the graphene membrane with bivalent cations compared to the monovalent cations. Later, bi-ionic potential measurements are conducted to confirm the differences in the interaction of cations. In Figure 2, the ionic strength is plotted instead of the absolute concentration. The ionic strength of the used bivalent salts is 3 times higher than that of the monovalent salts for a given ionic concentration. For $\mathrm{KCl}$, the Donnan plateau is observed at around $30 \mathrm{mV}$, which is $72 \%$ of the theoretical Nernst potential $[(R T / z F) \ln 5=41.3 \mathrm{mV}]$. For both of the bivalent salts, $\mathrm{CaCl}_{2}$ and $\mathrm{MgCl}_{2}$, a lower Donnan potential is obtained in comparison to the monovalent salts within the same ionic strength range (between 0.3 and $1.5 \mathrm{mM}$ ). The Donnan plateau is approximately $10 \mathrm{mV}$, which is only about 


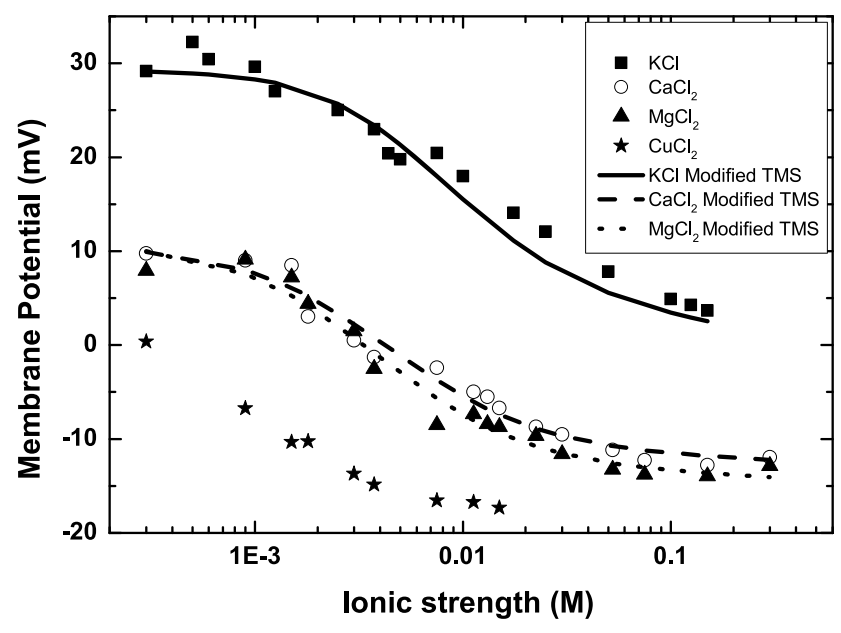

Figure 2. Membrane potential (experimental and fitted with the modified TMS model) versus ionic strength for $\mathrm{KCl}, \mathrm{MgCl}_{2}, \mathrm{CaCl}_{2}$, and $\mathrm{CuCl}_{2} . \mathrm{C}_{1} / \mathrm{C}_{2}$ is kept at 5 .

$50 \%$ of the theoretical Nernst potential $(20.6 \mathrm{mV})$. In the case of $\mathrm{CuCl}_{2}$, the membrane potential did not reach the Donnan plateau at the lowest ionic strength experimentally accessible. At concentrations lower than $0.1 \mathrm{mM}$, the membrane potential is very noisy and not reliable anymore. For the entire range of the ionic strength, the membrane potential remained positive for monovalent $\mathrm{KCl}$, implying a cation-selective nature of the membrane. With an increase in the ionic strength, the membrane becomes non-selective and the diffusion potential appears. At very high concentrations, the potential as a result of diffusion is expected to approach 0 because $\mathrm{K}^{+}$and $\mathrm{Cl}^{-}$ions have similar diffusion coefficients, as already reported in our previously published paper. ${ }^{15}$ For bivalent cations $\left(\mathrm{Mg}^{2+}\right.$ and $\left.\mathrm{Ca}^{2+}\right)$, the potential reaches a plateau around $-14 \mathrm{mV}$ for $\mathrm{MgCl}_{2}$ and around $-12 \mathrm{mV}$ for $\mathrm{CaCl}_{2}$. These values correspond well to the diffusion potential of the respective ion pairs. The Donnan plateaus for both $\mathrm{CaCl}_{2}$ and $\mathrm{MgCl}_{2}$ are similar, and their transition from the Donnan regime to the diffusion regime occurs at the same ionic strength. In contrast to $\mathrm{CaCl}_{2}$ and $\mathrm{MgCl}_{2}$ salts, $\mathrm{CuCl}_{2}$ reaches its diffusion potential regime at a lower ionic strength, suggesting a lower effective fixed charge on the membrane. The value of the diffusion potential (around $-16 \mathrm{mV}$ ) again corresponds to the potential generated as a result of the faster moving $\mathrm{Cu}^{2+}$ ions than the $\mathrm{Cl}^{-}$ions.

For the modified TMS theory, it was not possible to fit the $\mathrm{CuCl}_{2}$ data because experiments did not reveal a clear Donnan plateau at the lowest ionic strength experimentally accessible in our work. The fitted values for other salts are shown in Table 1 , where $\bar{C}_{\mathrm{R}}$ represents the effective fixed ion concentration in the membrane, $\alpha$ is the factor taking care of non-idealities present in the membrane, and $\bar{u}_{-} / \bar{u}_{+}$represents the ratio of anion to cation diffusivity inside the membrane.

Table 1. Fitting Parameters for Salts with a $C_{1} / C_{2}$ Ratio of 5 and their $95 \%$ Confidence Intervals

\begin{tabular}{lcccc}
\multicolumn{1}{c}{ salt } & $\bar{C}_{\mathrm{R}}(\mathrm{mM})$ & $\alpha$ & $\bar{u}_{-} / \bar{u}_{+}$ & bulk $\left(u_{-} / u_{+}\right)$ \\
$\mathrm{KCl}$ & $21.3 \pm 3.8$ & $0.72 \pm 0.02$ & $0.81 \pm 0.04$ & 1.04 \\
$\mathrm{MgCl}_{2}$ & $10.3 \pm 2.2$ & $0.53 \pm 0.07$ & $2.85 \pm 0.16$ & 2.87 \\
$\mathrm{CaCl}_{2}$ & $11.6 \pm 2.5$ & $0.52 \pm 0.06$ & $2.61 \pm 0.015$ & 2.56
\end{tabular}

The fitted value of $\bar{C}_{\mathrm{R}}$ for $\mathrm{KCl}(21.3 \mathrm{mM})$ is approximately twice the value for $\mathrm{MgCl}_{2}$ and $\mathrm{CaCl}_{2}$ (10.3 and $11.6 \mathrm{mM}$, respectively). The non-ideality factor $\alpha$ is 0.72 for $\mathrm{KCl}$ and around 0.5 for the bivalent salts, which indicates that the membrane is more selective for potassium cations than for bivalent cations. The fact that the $\bar{C}_{R}$ values for the bivalent salts are the same explains the similar transition regime of both of the salts. The ratio of diffusivities $\left(\bar{u}_{-} / \bar{u}_{+}\right)$of ions for $\mathrm{MgCl}_{2}$ and $\mathrm{CaCl}_{2}$ matches well with the bulk diffusivity ratios $\left(u_{-} / u_{+}\right)$ for these salts. This is unlike the case for their diffusivity ratios in ion-exchange membranes. ${ }^{19}$ Graphene is atomically thin, which may explain the small changes in the diffusivities of ions inside the membrane. To properly describe the diffusion regime, we have incorporated the activity coefficients of the ions to compute the activity of the ionic solution. At the higher ionic strengths, the ratio of activity coefficients may not necessarily be constant. The details of the calculation of the activity coefficients are provided in the Supporting Information. As discussed, the membrane potential values for $\mathrm{CuCl}_{2}$ could not be fit with the modified TMS model as a result of the absence of a Donnan potential plateau. However, the overall curve seems to be shifted to the lower ionic strength, and this indicates that, for $\mathrm{CuCl}_{2}$, the effective $\bar{C}_{\mathrm{R}}$ is even lower than the other two bivalent salts.

Our results clearly show that the same membrane is less selective for salts with bivalent counterions in the Donnan plateau regime. A plausible explanation for the reduced cationselective behavior of the membrane can be the overcompensation of surface charge at the graphene pore by the bivalent cations compared to the monovalent cations. At a higher ionic strength, the membrane potential becomes negative for $\mathrm{MgCl}_{2}, \mathrm{CaCl}_{2}$, and $\mathrm{CuCl}_{2}$, as expected from their corresponding ionic mobilities (Figure 1). The expected membrane potential for the bivalent salts from the TMS model shows that the diffusion potential for $\mathrm{MgCl}_{2}$ is around -15 $\mathrm{mV}$, the diffusion potential for $\mathrm{CaCl}_{2}$ is around $-14 \mathrm{mV}$, and the diffusion potential for $\mathrm{CaCl}_{2}$ is around $-16 \mathrm{mV}$, which is similar to our experimentally observed values. Our results suggest that the bivalent cations adsorb on the surface of the membrane and screen the surface charge of the pore, which reduces the membrane selectivity. However, $\mathrm{CuCl}_{2}$ behaves quite differently from the other two bivalent salts. We theoretically expect it to behave like the other bivalent salts, as shown in Figure 1. The experimentally observed difference is possibly due to the stronger adsorption of $\mathrm{Cu}^{2+}$ ions on graphene than the other two cations. Usually, the adsorption affinity depends upon the size of the ion, but all three bivalent ions have similar hydrated radii. ${ }^{46}$ The reason for higher $\mathrm{Cu}^{2+}$ adsorption may be caused by the different electronic structure of $\mathrm{Cu}^{2+}$ ions compared to $\mathrm{Mg}^{2+}$ and $\mathrm{Ca}^{2+}$ ions.

To further investigate these differences in interaction experimentally, we have conducted bi-ionic potential measurements. ${ }^{18,34,35}$ In this method, we have first selected one pair of salts, which have different cations but similar anions. We have kept the same cationic strength on both sides of the membrane and have conducted our experiments in two regimes. One is in the Donnan-dominated regime, and the other is outside the Donnan-dominated regime. In the Donnan-dominated regime, the membrane remains cation-selective and the membrane potential measured in this regime is due to the transport of the cations and a separation factor $\left(K_{\mathrm{A}}^{\mathrm{B}}\right)$ as a result of the differences in affinities of the ions toward the membrane. This implies that, if the membrane has higher affinity toward one 
type of ion (A or B), it will facilitate its transport. Outside the Donnan-dominated regime, the membrane loses its selectivity.

In our measurements, we have taken the following pair of salts: $\mathrm{LiCl} / \mathrm{KCl}, \mathrm{NH}_{4} \mathrm{Cl} / \mathrm{KCl}$, and $\mathrm{K}_{2} \mathrm{SO}_{4} / \mathrm{KCl}$. For bivalent cation salts, we selected $\mathrm{MgCl}_{2} / \mathrm{CaCl}_{2}$ and $\mathrm{MgCl}_{2} / \mathrm{CuCl}_{2}$. We have measured the bi-ionic potential experimentally for each pair of salts. Now, theoretically, we have determined the expected potential by taking the self-diffusion coefficient of the ions in the bulk and the separation factor to be 1 and we call it the ideal bi-ionic potential. In the ideal bi-ionic potential calculation, we have also taken into account the activity coefficient. In our earlier work, we have already observed that the ion diffusion coefficient ratio for graphene nanopores is similar to the bulk diffusion coefficient ratio. ${ }^{15}$ The separation factor $\left(K_{\mathrm{A}}^{\mathrm{B}}\right)$ is evaluated from eq 3 by inserting the experimental bi-ionic potential, diffusion coefficients, and activity coefficients of the ions under investigation. Table 2

Table 2. Experimental and Ideal Bi-ionic Potential for Salt Pairs in the Donnan-Dominated Regime

\begin{tabular}{llcc}
\multicolumn{1}{c}{ salt pair } & $\begin{array}{c}\text { concentration } \\
(\mathrm{mM})\end{array}$ & $\begin{array}{c}\text { measured bi-ionic } \\
\text { potential }(\mathrm{mV})\end{array}$ & $\begin{array}{c}\text { ideal bi-ionic } \\
\text { potential }(\mathrm{mV})\end{array}$ \\
$\mathrm{KCl} / \mathrm{LiCl}$ & 0.3 & -12.46 & -16.41 \\
$\mathrm{KCl} / \mathrm{NH}_{4} \mathrm{Cl}$ & 0.3 & 0 & 0 \\
$\mathrm{KCl} / \mathrm{K}_{2} \mathrm{SO}_{4}$ & $0.6 / 0.3$ & -3.15 & 0 \\
$\mathrm{MgCl}_{2} / \mathrm{CaCl}_{2}$ & 0.3 & 1.53 & 1.47 \\
$\mathrm{MgCl}_{2} / \mathrm{CuCl}_{2}$ & 0.3 & -1.99 & 0.14 \\
\hline
\end{tabular}

shows the experimental and ideal values of the bi-ionic potential in the low-concentration Donnan-dominated regime. For the $\mathrm{KCl} / \mathrm{LiCl}$ pair, the experimental value is different than the ideal value. The calculated selectivity factor is 0.86 , which is close to the ratio of the $\alpha$ values of $\mathrm{LiCl}$ and $\mathrm{KCl}$ salts (0.84) in our previously published paper. ${ }^{15}$ This indicates that the graphene membrane has a difference in affinity for $\mathrm{Li}^{+}$and $\mathrm{K}^{+}$ ions, which leads to two distinct Donnan plateaus for these two salts. The results for the $\mathrm{KCl} / \mathrm{NH}_{4} \mathrm{Cl}$ salt pair are shown in Figure 3. We observe that, for these two salts, the membrane potential versus ionic strength plots almost completely overlap. This behavior is also evident in our bi-ionic membrane potential measurements. Because $\mathrm{NH}_{4}^{+}$and $\mathrm{K}^{+}$ions have similar diffusivities, the expected theoretical potential is around

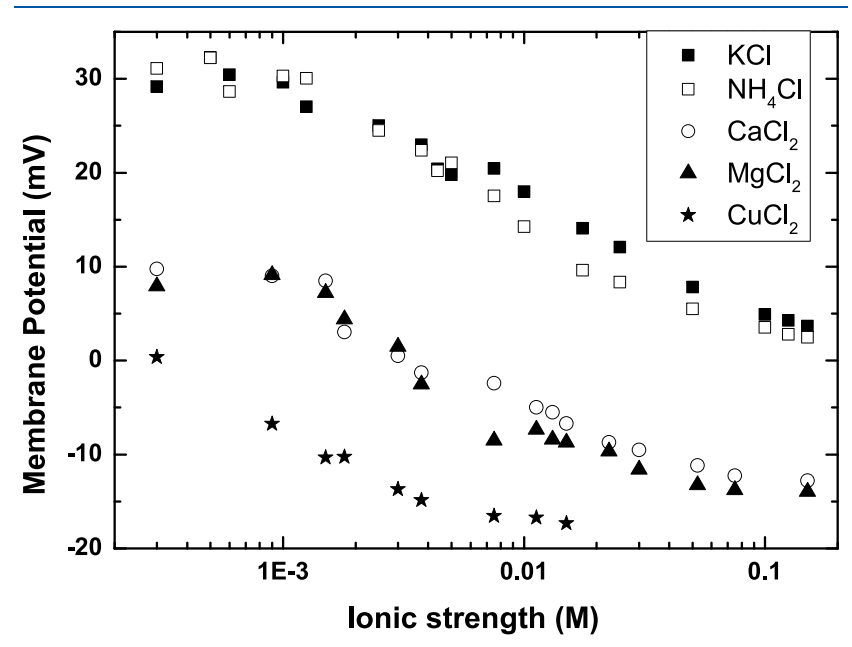

Figure 3. Membrane potential versus ionic strength, including $\mathrm{NH}_{4} \mathrm{Cl}$ salt.
$0 \mathrm{mV}$. Our experimentally observed membrane potential is also around $0 \mathrm{mV}$, which indicates that the membrane has similar affinities for both of the ions. The calculated $K_{\mathrm{A}}^{\mathrm{B}}$ value for the $\mathrm{KCl} / \mathrm{NH}_{4} \mathrm{Cl}$ salt pair is 1.01 , which is again similar to the ratio of $\alpha$ values for these two salts, i.e., 1.04 . For the $\mathrm{K}_{2} \mathrm{SO}_{4} / \mathrm{KCl}$ pair, ideally, the measured potential should be 0 . We have observed a finite potential value for this case, which matches our experimental observation of different Donnan plateaus for $\mathrm{K}_{2} \mathrm{SO}_{4} / \mathrm{KCl}$. In our previous work, we found that the ratio of $\alpha$ for the $\mathrm{K}_{2} \mathrm{SO}_{4} / \mathrm{KCl}$ salt pair is higher than 1 (1.10), which is consistent with the bi-ionic potential measurement. For the bivalent ion pair $\mathrm{MgCl}_{2} / \mathrm{CaCl}_{2}$, the measured and ideal values of the bi-ionic potential are almost similar, which is also reflected in Figure 2, where the plots for these two salts almost overlap. The calculated value of $K_{\mathrm{A}}^{\mathrm{B}}$ for this case is 1.00 , which again matches quite well with the ratio of $\alpha$ values (1.02) for these two salts. This indicates that the membrane has similar affinity for transport of $\mathrm{Mg}^{2+}$ and $\mathrm{Ca}^{2+}$ ions. Our membrane potential versus ionic strength data for $\mathrm{Cu}^{2+}$ ions show completely different behavior in comparison to other bivalent ions. $\mathrm{Mg}^{2+}$ and $\mathrm{Cu}^{2+}$ ions having similar bulk diffusivities should result in an ideal bi-ionic potential that is almost 0 $(0.14 \mathrm{mV})$, while our experimental result shows a value of -2 $\mathrm{mV}$ in the Donnan-dominated regime, which implies a different interaction of $\mathrm{Cu}^{2+}$ and $\mathrm{Mg}^{2+}$ ions with the graphene membrane. The evaluated $K_{\mathrm{A}}^{\mathrm{B}}$ value for this salt pair is 1.18 , which confirms the difference in the interactions. We could not compare this value for the $\alpha$ ratio in this case because we have not reached the Donnan plateau for $\mathrm{CuCl}_{2}$ salt.

For the experiments outside the Donnan-dominated regime, the membrane loses cation selectivity because of increased screening of charges at a higher concentration. At this point, for all of the salt pairs, the measured value of bi-ionic potential approaches the ideal value, except for the $\mathrm{KCl} / \mathrm{K}_{2} \mathrm{SO}_{4}$ pair (Table 3).

Table 3. Experimental and Ideal Bi-ionic Potential for Salt Pairs Outside the Donnan-Dominated Regime

\begin{tabular}{lccc}
\multicolumn{1}{c}{ salt pair } & $\begin{array}{c}\text { concentration } \\
(\mathrm{mM})\end{array}$ & $\begin{array}{c}\text { measured bi-ionic } \\
\text { potential }(\mathrm{mV})\end{array}$ & $\begin{array}{c}\text { ideal bi-ionic } \\
\text { potential }(\mathrm{mV})\end{array}$ \\
$\mathrm{KCl} / \mathrm{LiCl}$ & 10 & -15.57 & -16.31 \\
$\mathrm{KCl} / \mathrm{NH}_{4} \mathrm{Cl}$ & 10 & 0 & 0 \\
$\mathrm{KCl} / \mathrm{K}_{2} \mathrm{SO}_{4}$ & 10 & -1 & 0 \\
$\mathrm{MgCl}_{2} / \mathrm{CaCl}_{2}$ & 10 & 1.37 & 1.26 \\
$\mathrm{MgCl}_{2} / \mathrm{CuCl}_{2}$ & 10 & 0.62 & -0.12 \\
\hline
\end{tabular}

$K_{\mathrm{A}}^{\mathrm{B}}$ depends upon the concentrations of the electrolyte solution and, thereby, depends upon the activity coefficients of the salts. At higher concentrations, the activity coefficient of the ions (and ratio of these) deviates from 1, which is incorporated in the given bi-ionic potential equation. The reason for the non-zero value of bi-ionic potential for $\mathrm{KCl}$ / $\mathrm{K}_{2} \mathrm{SO}_{4}$ is possibly due to the fact that the counterions having two different valencies of anions have a net transport through the membrane. Because the membrane is not perfectly selective even in the Donnan-dominated regime as shown in our previous study, there will be some counterions moving through the membrane. We have performed measurements for more than one salt concentration, which is shown in the Supporting Information. This confirms that our measurement is consistent at other salt concentrations as well. 
MD simulation studies support our observation that differences in the Donnan plateaus and Donnan regimes with different ions can be due to differences in the interactions of ions with the graphene nanopores based on their chemical termination. ${ }^{25-28,28-31}$

The membrane potential measurements for bivalent cations suggest that the bivalent ions adsorb on the graphene surface. To investigate the reversibility of the surface adsorption, we conducted the following experiment. After our study with $\mathrm{MgCl}_{2}$ and $\mathrm{CaCl}_{2}$, we used the same membrane to perform the experiment once again with monovalent $\mathrm{KCl}$ with the same salt concentration ratio of 5 . We now observed a lower value for the membrane potential for the same ionic strength, as if the membrane was less selective. Figure 4 shows the membrane

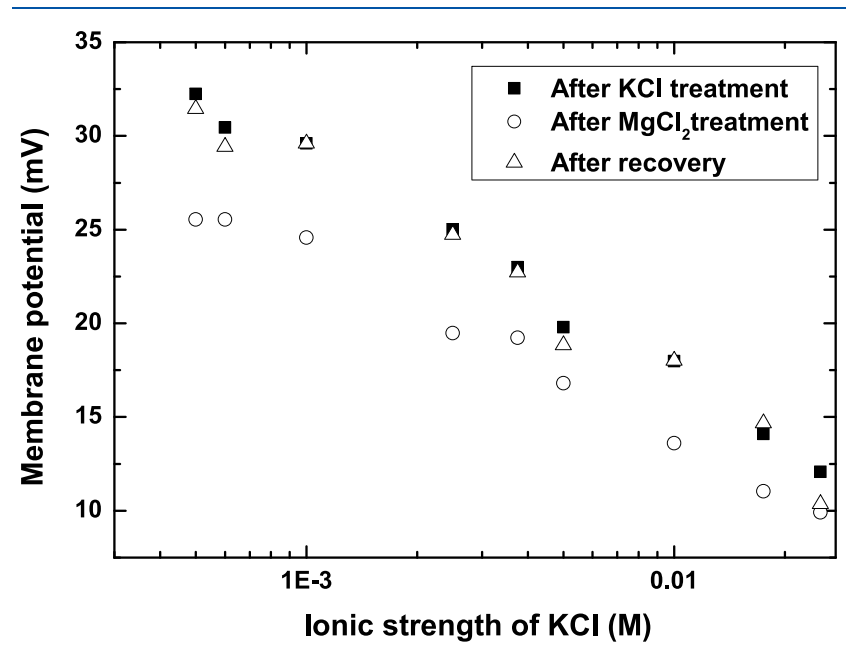

Figure 4. Membrane potential versus ionic strength after bivalent ion treatment and after recovery of the membrane. $C_{1} / C_{2}$ is kept at 5 .

potential for $\mathrm{KCl}$, after being exposed to bivalent salts and after the membrane is recovered by treating it with monovalent $\mathrm{KCl}$. After the membrane was contacted with bivalent salts, the membrane potential for $\mathrm{KCl}$ is around $4-6 \mathrm{mV}$ lower than the value that we obtained previously. The difference in the membrane potential is larger at the low ionic strength compared to the higher ionic strength. The reduced Donnan potential for $\mathrm{KCl}$ after exposure to $\mathrm{MgCl}_{2}$ can be understood from the adsorption of bivalent cations to the membrane surface. This adsorption lowers the membrane charge and, thus, selectivity, giving lower Donnan potential values. As we see in Figure 4, at a very high concentration, both of the curves tend to converge at a value around $0 \mathrm{mV}$ because both $\mathrm{K}^{+}$and $\mathrm{Cl}^{-}$ions have similar diffusivities in the membrane. After subsequent exposure to $1 \mathrm{M} \mathrm{KCl}$, we found that the initial membrane performance was recovered. The same recovery was observed when the membrane was immersed in $\mathrm{HCl}(\mathrm{pH}$ 1.89 ) overnight. The high concentration of monovalent cations results in a complete exchange of the adsorbed bivalent cations.

\section{CONCLUSION}

In our work, we have investigated the interaction of mono- and bivalent cations with perforated graphene membranes. When the ionic strengths of salts on both sides of the membrane are varied, keeping a constant ratio, the membrane potentials for $\mathrm{MgCl}_{2}$ and $\mathrm{CaCl}_{2}$ follow a trend similar to that predicted by a modified TMS theory for dense ion-exchange membranes. A Donnan potential plateau is observed at the low ionic strengths, and a diffusion potential plateau is observed at higher ionic strengths. The Donnan potential observed for both $\mathrm{MgCl}_{2}$ and $\mathrm{CaCl}_{2}$ is much lower than the theoretical Nernst potential (50\%) and that observed for monovalent $\mathrm{KCl}$ ( $72 \%$ of its corresponding Nernst potential). $\mathrm{MgCl}_{2}$ and $\mathrm{CaCl}_{2}$ reach the diffusion potential limit already at an ionic strength, where $\mathrm{KCl}$ has still not reached its diffusion-dominated regime. For $\mathrm{CuCl}_{2}$, the Donnan-dominated regime is not reached, while the diffusion-dominated regime is reached at a lower ionic strength compared to the other salts. Although a complete fit with the TMS model could not be made, the location of the transition between Donnan- and diffusiondominated regimes suggests that the fixed ion charge on the membrane is lowest for the experiments with $\mathrm{CuCl}_{2}$. A possible explanation for these effects is that the bivalent cations adsorb on the single-layer graphene, thereby reducing its effective surface charge. Hence, the observed Donnan potential is much lower than the theoretical Nernst potential. Among the bivalent cations, $\mathrm{Cu}^{2+}$ seems to adsorb the most strongly.

Further experiments have validated our hypothesis on bivalent cation adsorption. Membranes previously exposed to $\mathrm{MgCl}_{2}$ and $\mathrm{CaCl}_{2}$ show a reduced potential value for $\mathrm{KCl}$ at low ionic strength. This indicates that the adsorbed ions are strongly attached to the surface and are not easily removed. Nevertheless, recovery of the membrane selectivity is possible by immersing the membrane in $1 \mathrm{M} \mathrm{KCl}$ or $\mathrm{HCl}(\mathrm{pH} 1.89)$.

We have found that the membrane behaves as a weakly charged nanofiltration membrane, having differences in affinities for different cation ions in the Donnan-dominated regime. This leads to different Donnan plateaus for different salts. The experimental bi-ionic potential for $\mathrm{LiCl} / \mathrm{KCl}$ is found to be different from the ideal theoretical bi-ionic potential. This implies that the membrane has separate affinity toward these ions $\left(\mathrm{K}^{+}>\mathrm{Li}^{+}\right)$, resulting in different Donnan plateaus for these two salts. For $\mathrm{KCl} / \mathrm{K}_{2} \mathrm{SO}_{4}$, the ideal bi-ionic potential should be 0 . We found a non-zero value of for the bi-ionic potential for this case, which is due to possible transport of coions through the non-ideal graphene. Ions that have similar affinities toward the membrane $\left(\mathrm{Mg}^{2+} / \mathrm{Ca}^{2+}\right.$ and $\left.\mathrm{NH}_{4}^{+} / \mathrm{K}^{+}\right)$ have a similar value for the membrane potential in the Donnan-dominated regime. For the $\mathrm{Mg}^{2+} / \mathrm{Cu}^{2+}$ pair, the biionic potential should ideally be zero; however, we measured a non-zero value for this salt pair. This implies that the membrane has differences in affinities toward these two ions. It is difficult to comment on which ion has higher affinity for transport in this case because we have not reached the Donnan plateau for $\mathrm{CuCl}_{2}$ and other phenomena, such as adsorption on the graphene surface, are expected in the case of $\mathrm{Cu}^{2+}$ ions. We quantified the selectivity and showed that the values are a good match with the ratio of $\alpha$ values for the corresponding salts. Our work provides a clear indication of different interactions of bivalent cations with a two-dimensional (2D) porous graphene membrane. Their relation to selective ion transport through these graphene-based membranes in comparison to monovalent cations opens up new avenues upon further investigation of ion transport phenomena with $2 \mathrm{D}$ materials in this field.

\section{ASSOCIATED CONTENT}

\section{Supporting Information}

The Supporting Information is available free of charge at https://pubs.acs.org/doi/10.1021/acs.langmuir.0c00924.

Theory and supporting experiments (PDF) 


\section{AUTHOR INFORMATION}

\section{Corresponding Authors}

Jeffery A. Wood - Soft Matter, Fluidics and Interfaces, Faculty of Science and Technology, University of Twente, 7500 AE Enschede, Netherlands; (1) orcid.org/0000-0002-9438-1048; Phone: +31-53-4894798; Email: j.a.wood@utwente.nl

Rob G. H. Lammertink - Soft Matter, Fluidics and Interfaces, Faculty of Science and Technology, University of Twente, 7500 AE Enschede, Netherlands; 10 orcid.org/0000-0002-08272946; Phone: +31-53-4894798; Email: r.g.h.lammertink@ utwente.nl

\section{Authors}

Mandakranta Ghosh - Soft Matter, Fluidics and Interfaces, Faculty of Science and Technology, University of Twente, 7500 AE Enschede, Netherlands

Lukas Madauß - Fakultät für Physik und CENIDE, Universität Duisburg-Essen, 47048 Duisburg, Germany; 이이.org/ 0000-0003-2556-5967

Marika Schleberger - Fakultät für Physik und CENIDE, Universität Duisburg-Essen, 47048 Duisburg, Germany; (1) orcid.org/0000-0002-5785-1186

Henning Lebius - Normandie University, ENSICAEN, UNICAEN, CEA, CNRS, CIMAP, 14050 Caen, France

Abdenacer Benyagoub - Normandie University, ENSICAEN, UNICAEN, CEA, CNRS, CIMAP, 14050 Caen, France

Complete contact information is available at: https://pubs.acs.org/10.1021/acs.langmuir.0c00924

\section{Notes}

The authors declare no competing financial interest.

\section{ACKNOWLEDGMENTS}

The work is performed under the NU-TEGRAM project funded by NWO-I with Project 15FLAG02, ANR under ANR15-GRFL-0002, and DFG under SCHL 384/16-1, Project 279028710. The authors thank Timon Rijnaarts, Harmen Zwijnenberg, and all our project partners of NU-TEGRAM for useful discussions. The authors also thank the facility of GANIL, France, for ion beam irradiation.

\section{REFERENCES}

(1) Pintauro, P. N.; Verbrugge, M. W. The Electric-potential Profile In Ion-exchange Membrane Pores. J. Membr. Sci. 1989, 44, 197-212.

(2) Li, J.; Zhu, J.; Yuan, S.; Lin, J.; Shen, J.; Van der Bruggen, B. Cation-Exchange Membranes with Controlled Porosity in Electrodialysis Application. Ind. Eng. Chem. Res. 2017, 56, 8111-8120.

(3) Tanaka, Y. Ion-Exchange Membrane Electrodialysis for Saline Water Desalination and Its Application to Seawater Concentration. Ind. Eng. Chem. Res. 2011, 50, 7494-7503.

(4) Geise, G. M.; Cassady, H. J.; Paul, D. R.; Logan, B. E.; Hickner, M. A. Specific Ion Effects on Membrane Potential and The Permselectivity of Ion Exchange Membranes. Phys. Chem. Chem. Phys. 2014, 16, 21673-21681.

(5) Wills, G. B.; Lightfoot, E. N. Transport Phenomena in IonExchange Membranes. Ind. Eng. Chem. Fundam. 1966, 5, 114-120.

(6) Rijnaarts, T.; Huerta, E.; van Baak, W.; Nijmeijer, K. Effect of Divalent Cations on RED Performance and Cation Exchange Membrane Selection to Enhance Power Densities. Environ. Sci. Technol. 2017, 51, 13028-13035.

(7) Cohen-Tanugi, D.; Grossman, J. C. Water Desalination Across Nanoporous Graphene. Nano Lett. 2012, 12, 3602-3608.

(8) Celebi, K.; Buchheim, J.; Wyss, R. M.; Droudian, A.; Gasser, P.; Shorubalko, I.; Kye, J.-I. J.-I.; Lee, C.; Park, H. G. Ultimate
Permeation Across Atomically Thin Porous Graphene. Science 2014, 344, 289-292.

(9) Hu, S.; Lozada-Hidalgo, M.; Wang, F. C.; Mishchenko, A.; Schedin, F.; Nair, R. R.; Hill, E. W.; Boukhvalov, D. W.; Katsnelson, M. I.; Dryfe, R. A.; Grigorieva, I. V.; Wu, H. A.; Geim, A. K. Proton Transport Through One-Atom-Thick Crystals. Nature 2014, 516, 227-230.

(10) Jang, D.; Idrobo, J. C.; Laoui, T.; Karnik, R. Water and Solute Transport Governed by Tunable Pore Size Distributions in Nanoporous Graphene Membranes. ACS Nano 2017, 11, 10042-10052.

(11) Koenig, S. P.; Wang, L.; Pellegrino, J.; Bunch, J. S. Selective Molecular Sieving Through Porous Graphene. Nat. Nanotechnol. 2012, 7, 728-732.

(12) Rollings, R. C.; Kuan, A. T.; Golovchenko, J. A. Ion Selectivity of Graphene Nanopores. Nat. Commun. 2016, 7, 11408.

(13) O’Hern, S. C.; Stewart, C. A.; Boutilier, M. S. H.; Idrobo, J. C.; Bhaviripudi, S.; Das, S. K.; Kong, J.; Laoui, T.; Atieh, M.; Karnik, R. Selective Molecular Transport Through Intrinsic Defects in a Single layer of CVD Graphene. ACS Nano 2012, 6, 10130-10138.

(14) Wyss, R. M.; Tian, T.; Yazda, K.; Park, H. G.; Shih, C.-J. Macroscopic Salt Rejection through Electrostatically Gated Nanoporous Graphene. Nano Lett. 2019, 19, 6400-6409.

(15) Ghosh, M.; Jorissen, K. F. A.; Wood, J. A.; Lammertink, R. G. H. Ion Transport Through Perforated Graphene. J. Phys. Chem. Lett. 2018, 9, 6339-6344.

(16) Madauß, L.; Schumacher, J.; Ghosh, M.; Ochedowski, O.; Meyer, J.; Lebius, H.; Ban-d'Etat, B.; Toimil-Molares, M. E.; Trautmann, C.; Lammertink, R. G. H.; Ulbricht, M.; Schleberger, M. Fabrication of Nanoporous Graphene/Polymer Composite Membranes. Nanoscale 2017, 9, 10487-10493.

(17) Tanaka, Y. Ion Exchange Membranes: Fundamentals and Applications, 2nd ed.; Elsevier: Amsterdam, Netherlands, 2015; DOI: 10.1016/C2013-0-12870-X.

(18) Sata, T. Ion Exchange Membranes: Preparation, Characterization, Modification and Application; Royal Society of Chemistry: Cambridge, U.K., 2004; DOI: 10.1039/9781847551177.

(19) Goswami, A.; Acharya, A.; Pandey, A. K. Study of Self-Diffusion of Monovalent and Divalent Cations in Nafion-117 Ion-Exchange Membrane. J. Phys. Chem. B 2001, 105, 9196-9201.

(20) Yang, S.-T.; Chang, Y.; Wang, H.; Liu, G.; Chen, S.; Wang, Y.; Liu, Y.; Cao, A. Folding/Aggregation of Graphene Oxide and Its Application in $\mathrm{Cu}^{2+}$ Removal. J. Colloid Interface Sci. 2010, 351, 122 127.

(21) Yu, B.; Xu, J.; Liu, J.-H.; Yang, S.-T.; Luo, J.; Zhou, Q.; Wan, J.; Liao, R.; Wang, H.; Liu, Y. Adsorption Behavior of Copper Ions on Graphene Oxide-Chitosan Aerogel. J. Environ. Chem. Eng. 2013, 1, 1044-1050.

(22) Khannanov, A.; Gareev, B.; Batalin, G.; Amirova, L. M.; Dimiev, A. M. Counterion Concentration Profiles at the Graphene Oxide/Water Interface. Langmuir 2019, 35, 13469-13479.

(23) Rosenberg, N. W.; George, J. H. B.; Potter, W. D. Electrochemical Properties of a Cation-Transfer Membrane. J. Electrochem. Soc. 1957, 104, 111-115.

(24) Caglar, M.; Silkina, I.; Brown, B. T.; Thorneywork, A. L.; Burton, O. J.; Babenko, V.; Gilbert, S. M.; Zettl, A.; Hofmann, S.; Keyser, U. F. Tunable Anion-Selective Transport through Monolayer Graphene and Hexagonal Boron Nitride. ACS Nano 2020, 14, 27292738.

(25) Cohen-Tanugi, D.; Grossman, J. C. Water Desalination across Nanoporous Graphene. Nano Lett. 2012, 12, 3602-3608.

(26) Achtyl, J. L.; Vlassiouk, I. V.; Surwade, S. P.; Fulvio, P. F.; Dai, S.; Geiger, F. M. Interaction of Magnesium Ions with Pristine SingleLayer and Defected Graphene/Water Interfaces Studied by Second Harmonic Generation. J. Phys. Chem. B 2014, 118, 7739-7749.

(27) Jiang, G.; Cheng, C.; Li, D.; Liu, J. Z. Molecular Dynamics Simulations of The Electric Double Layer Capacitance of Graphene Electrodes in Mono-valent Aqueous Electrolytes. Nano Res. 2016, 9, 174-186. 
(28) He, Z.; Zhou, J.; Lu, X.; Corry, B. Bioinspired Graphene Nanopores with Voltage-Tunable Ion Selectivity for $\mathrm{Na}+$ and $\mathrm{K}+$. ACS Nano 2013, 7, 10148-10157.

(29) Wang, Y.; He, Z.; Gupta, K. M.; Shi, Q.; Lu, R. Molecular Dynamics Study on Water Desalination Through Functionalized Nanoporous Graphene. Carbon 2017, 116, 120-127.

(30) Ruan, Y.; Zhu, Y.; Zhang, Y.; Gao, Q.; Lu, X.; Lu, L. Molecular Dynamics Study of $\mathrm{Mg}^{2+} / \mathrm{Li}^{+}$Separation via Biomimetic GrapheneBased Nanopores: The Role of Dehydration in Second Shell. Langmuir 2016, 32, 13778-13786.

(31) Dočkal, J.; Moučka, F.; Lísal, M. Molecular Dynamics of Graphene-Electrolyte Interface: Interfacial Solution Structure and Molecular Diffusion. J. Phys. Chem. C 2019, 123, 26379-26396.

(32) Dammak, L.; Lteif, R.; Larchet, C.; Auclair, B. Water Transport in Bi-ionic systems: Theoretical Treatment and Effect on The Bi-ionic Potential. New J. Chem. 1998, 22, 605-608.

(33) Toyoshima, Y.; Nozaki, H. Biionic potential across charged membranes. J. Phys. Chem. 1970, 74, 2704-2710.

(34) Dammak, L.; Larchet, C.; Auclair, B. Theoretical Study of the Bi-ionic Potential and Confrontation with Experimental Results. J. Membr. Sci. 1999, 155, 193-207.

(35) Guirao, A.; Mafe, S.; Manzanares, J. A.; Ibanez, J. A. Biionic Potential of Charged Membranes: Effects of the Diffusion Boundary Layers. J. Phys. Chem. 1995, 99, 3387-3393.

(36) Li, S. X.; Guan, W.; Weiner, B.; Reed, M. A. Direct Observation of Charge Inversion in Divalent Nanofluidic Devices. Nano Lett. 2015, $15,5046-5051$

(37) van der Heyden, F. H. J.; Stein, D.; Besteman, K.; Lemay, S. G.; Dekker, C. Charge Inversion at High Ionic Strength Studied by Streaming Currents. Phys. Rev. Lett. 2006, 96, 224502.

(38) Nguyen, T. T.; Grosberg, A. Y.; Shklovskii, B. I. Macroions in Salty Water with Multivalent Ions: Giant Inversion of Charge. Phys. Rev. Lett. 2000, 85, 1568-1571.

(39) Tanaka, M.; Grosberg, A. Y. Giant Charge Inversion of a Macroion Due to Multivalent Counterions and Monovalent Coions: Molecular Dynamics Study. J. Chem. Phys. 2001, 115, 567-574.

(40) van Deursen, P. M. G.; Tang, Z.; Winter, A.; Mohn, M. J.; Kaiser, U.; Turchanin, A. A.; Schneider, G. F. Selective Ion Sieving Through Arrays of Sub-nanometer Nanopores in Chemically Tunable 2D Carbon membranes. Nanoscale 2019, 11, 20785-20791.

(41) Galizia, M.; Benedetti, F. M.; Paul, D. R.; Freeman, B. D. Monovalent and Divalent Ion Sorption in a Cation Exchange Membrane Based on Cross-Linked Poly (P-Styrene Sulfonate-CoDivinylbenzene). J. Membr. Sci. 2017, 535, 132-142.

(42) Shang, W. J.; Wang, X. L.; Yu, Y. X. Theoretical Calculation on the Membrane Potential of Charged Porous Membranes in 1-1, 1-2, 2-1 and 2-2 Electrolyte Solutions. J. Membr. Sci. 2006, 285, 362375.

(43) Vanýsek, P. CRC Handbook of Chemistry and Physics; CRC Press: Boca Raton, FL, 2005.

(44) Schleberger, M.; Kotakoski, J. 2D Material Science: Defect Engineering by Particle Irradiation. Materials 2018, 11, 1885.

(45) Vázquez, H.; Åhlgren, E.; Ochedowski, O.; Leino, A.; Mirzayev, R.; Kozubek, R.; Lebius, H.; Karlušic, M.; Jakšic, M.; Krasheninnikov, A.; Kotakoski, J.; Schleberger, M.; Nordlund, K.; Djurabekova, F. Creating Nanoporous Graphene With Swift Heavy Ions. Carbon 2017, 114, 511-518.

(46) Kielland, J. Individual Activity Coefficients of Ions in Aqueous Solutions. J. Am. Chem. Soc. 1937, 59, 1675-1678. 